\title{
Increasing jellyfish populations: trends in Large Marine Ecosystems
}

\author{
Lucas Brotz • William W. L. Cheung • \\ Kristin Kleisner • Evgeny Pakhomov • \\ Daniel Pauly
}

Published online: 3 April 2012

(C) The Author(s) 2012. This article is published with open access at Springerlink.com

\begin{abstract}
Although there are various indications and claims that jellyfish (i.e., scyphozoans, cubozoans, most hydrozoans, ctenophores, and salps) have been increasing at a global scale in recent decades, a rigorous demonstration of this has never been presented. Because this is mainly due to scarcity of quantitative time series of jellyfish abundance from scientific surveys, we attempt to complement such data with non-conventional information from other sources. This was accomplished using the analytical framework of fuzzy logic, which allows the
\end{abstract}

Guest editors: J. E. Purcell, H. Mianzan \& J. R. Frost / Jellyfish Blooms: Interactions with Humans and Fisheries

L. Brotz $(\bowtie) \cdot$ K. Kleisner $\cdot$ D. Pauly

Sea Around Us Project, Fisheries Centre, University of British Columbia, 2202 Main Mall, Vancouver, BC V6T 1Z4, Canada

e-mail: lucasbrotz@gmail.com

L. Brotz · E. Pakhomov

Department of Earth and Ocean Sciences, University of British Columbia, 6339 Stores Road, Vancouver,

BC V6T 1Z4, Canada

W. W. L. Cheung

School of Environmental Sciences, University of East Anglia, Norwich NR4 7TJ, UK

W. W. L. Cheung

Fisheries Centre, University of British Columbia, 2202 Main Mall, Vancouver, BC V6T 1Z4, Canada combination of information with variable degrees of cardinality, reliability, and temporal and spatial coverage. Data were aggregated and analyzed at the scale of Large Marine Ecosystem (LME). Of the 66 LMEs defined thus far that cover the world's coastal waters and seas, trends of jellyfish abundance after 1950 (increasing, decreasing, or stable/variable) were identified for 45 , with variable degrees of confidence. Of those 45 LMEs, the majority (28 or $62 \%$ ) showed increasing trends. These changes are discussed in the context of possible sources of bias and uncertainty, along with previously proposed hypotheses to explain increases in jellyfish.

Keywords Jellyfishes - Gelatinous zooplankton · Blooms · Pelagic cnidarians · Ctenophores · Fuzzy logic

\section{Introduction}

Jellyfish are a conspicuous, but relatively little studied component of marine ecosystems, whose populations fluctuate widely with ocean climate and also experience sudden outbursts known as "blooms," followed by population crashes (Purcell, 2005). There are also recent suggestions that jellyfish may be synanthropic, specifically, benefiting from human interactions with the oceans, and thus may be increasing globally (Mills, 2001; Purcell et al., 2007; Pauly et al., 2009a; Richardson et al., 2009). Previous global reviews of 
jellyfish populations (e.g., Mills, 2001; Purcell et al., 2007; Chudnow, 2008) show evidence of numerous localized increases; however, for most ecosystems, long time series of abundance measures for jellyfish are lacking, and the perceived widespread or global increase in jellyfish still lacks a rigorous foundation.

Establishing abundance trends for jellyfish is difficult due to a number of factors. There is a dearth of historical information on jellyfish, because they were usually damaged or not recorded when caught in routine bottom trawl or zooplankton surveys (Pugh, 1989; Hay, 2006). In fact, the latter often used gear designed to exclude jellyfish from plankton samples (e.g., Heinle, 1965) or were based on methodologies that explicitly recommended their removal before analysis (e.g., Dovel, 1964). For example, a classic manual on zooplankton sampling published by UNESCO (1968) mentions jellyfish only once, i.e., "Gelatinous organisms and other animals [...] will occur in the catches and these must be considered separately from the main sample."

Moreover, jellyfish are difficult to sample even when targeted (Omori \& Hamner, 1982; Pierce, 2009). As a result of their neglect in routine surveys and marine samples, jellyfish were generally perceived as a bothersome and unimportant component of marine ecosystems (Pauly et al., 2009a), which then justified their further neglect. Furthermore, despite recent advances in research and understanding of jellyfish ecology at local scales, such knowledge is rarely used to evaluate possible causes or consequences of jellyfish blooms at larger scales, or to make predictions (Purcell, 2009).

Their peculiar life cycles, which can result in extremely high temporal and spatial variability in abundance, peaking in the form of "blooms" (Mills, 2001; Purcell et al., 2007; Boero et al., 2008; Dawson \& Hamner, 2009; Hamner \& Dawson, 2009), also contribute to why jellyfish tend to be understudied. All cubozoans, as well as many hydrozoans and scyphozoans have a life history consisting of a sessile polyp phase and a planktonic medusa phase. Many polyps reproduce asexually through the process of strobilation, producing multiple ephyrae which join the zooplankton community (Arai, 1997) and rapidly grow to become medusae (Palomares \& Pauly, 2009). For some species, the polyps may asexually bud more polyps or form dormant cysts capable of surviving harsh environmental conditions (Arai, 2009). These characteristic life history traits make jellyfish suited to highly variable environments, because they can survive when conditions are unfavorable and rapidly reproduce when conditions are favorable (Boero et al., 2008; Richardson et al., 2009). Siphonophores, ctenophores, and salps lack a polyp phase, but can also reproduce rapidly under favorable conditions (Alldredge \& Madin, 1982; Purcell et al., 2007). Such varied reproductive strategies make it extremely difficult to assess jellyfish populations. Indeed, if few surveys have been conducted to quantify medusa abundance, even less is known about their polyps (Mills, 2001).

More attention has been paid to jellyfish in recent years because of their interference in human enterprises, their ecological importance, and their benefits to humans. Jellyfish directly interfere with many human activities (reviewed by Purcell et al., 2007; Richardson et al., 2009), specifically, through stings (beach closures, tourism impacts, injuries, deaths), clogging intakes (coastal power and desalination plants, mining and military operations, shipping, aquaria), interference with fishing (clogged and split nets, spoiled catch, stung fishers, damaged gear, capsized boats), aquaculture (fish deaths, pens fouled by polyps), and marine biological surveys (interference with trawls and acoustic surveys). Jellyfish also have ecosystem impacts with indirect effects on fisheries resources that are difficult to quantify, such as their roles as predators of zooplankton, fish eggs and ichthyoplankton, as vectors for parasites, as food for fish, and as refugia and food for some species of juvenile fish (interactions reviewed by Purcell \& Arai, 2001).

Some jellyfish also benefit humans (reviewed in Purcell et al., 2007), notably as food (Hsieh et al., 2001), and potentially for use in drugs (e.g., Sugahara et al., 2006; Ohta et al., 2009). The discovery, isolation, and development of a fluorescent protein from jellyfish led to a revolution in biotechnology (Zimmer, 2005) and a Nobel Prize (Coleman, 2010); however, the proteins now are synthesized in the laboratory. Unfortunately, such benefits may be outweighed by the direct and indirect negative impacts of jellyfish blooms.

The lack of jellyfish population datasets covering large temporal and spatial scales limits the scope of inferences that can be drawn about jellyfish on a global basis. To compensate for this, we used analytic methods designed to allow for the inclusion of a wide variety of information, including "anecdotal data," 
whose value is often underestimated (Pauly, 1995). Because the majority of recently reported changes in jellyfish populations around the globe occur in coastal waters or semi-enclosed seas (Mills, 2001; Purcell et al., 2007), the Large Marine Ecosystem (LME) framework provided a suitable stratification scheme to investigate these trends. We used the established system of fuzzy logic to examine the evidence for changes in jellyfish populations over recent decades.

\section{Materials and methods}

\section{Definition of "jellyfish"}

Because the term "jellyfish" lacks a formal definition, we present an operational definition used in this analysis, which will be used to refer to both single and multiple species. Here, the word "jellyfish" refers to gelatinous zooplankton that include medusae of the phylum Cnidaria (scyphomedusae, hydromedusae, cubomedusae, and siphonophores) and planktonic members of the phylum Ctenophora. We also included the pelagic tunicates known as salps due to their gelatinous nature, pulsed life cycles, and apparent response to changing oceanic conditions (Loeb et al., 1997; Atkinson et al., 2004; Lee et al., 2010). Especially sparse time series data on pyrosomes and doliolids prevented their inclusion in the analysis.

Other types of gelatinous zooplankton, such as appendicularians, mollusks, and chaetognaths, were not included in our analysis for various reasons (their small size, life history, ecological roles, high carbonto-weight ratio), and the fact that they are generally not considered jellyfish (see Mianzan \& Guerrero, 2000; Graham \& Bayha, 2007; Richardson et al., 2009). Pleustonic jellyfish, such those belonging to the genera Physalia, Porpita, and Velella, also were excluded because their local distribution is heavily influenced by wind patterns (Mackie, 1974). As such, locations reporting these species are frequently implicated in claims of "unprecedented" blooms and mass beach strandings lacking a historical context.

\section{LME approach and the 1950 baseline}

In order to examine and compare changes in jellyfish populations, data were stratified by LME. The LME framework defines boundaries based on ecological criteria rather than economic or political criteria (Sherman \& Hempel, 2009). LMEs may extend from nearshore areas, including river basins and estuaries, out to the seaward boundaries of continental shelves or coastal currents (Sherman \& Tang, 1999). Four sets of factors were considered when defining the physical extent of the LME boundaries, i.e., bathymetry, hydrography, productivity, and trophic relationships. LMEs range from $150,000 \mathrm{~km}^{2}$ to more than 5 million $\mathrm{km}^{2}$. To date, 66 LMEs have been described in terms of these parameters (Sherman \& Hempel, 2009), with emphasis on fisheries (Pauly et al., 2009b, see also www.seaaroundus.org).

In order to examine changes in jellyfish populations, a baseline must be selected. For our analysis, changes were only considered if they occurred after 1950 , notably because this was the first year for which the Food and Agriculture Organization of the United Nations (FAO) published its annual compendia of global fisheries catches (which now include jellyfish), part of an effort by the United Nations to "quantify the world" (Ward et al., 2004). Also, most of the reported changes in jellyfish populations stem from recent decades (Mills, 2001; Purcell et al., 2007); thus, a 1950 baseline provides the contrast required for comparison and testing of such reports. Finally, many of the anthropogenic factors that have been suggested as causes of recent increases in jellyfish populations have been quantified only since the mid-twentieth century, notably because they are derived from FAO data (e.g., Watson et al., 2004) and recently have been reexpressed at the LME scale (e.g., Maranger et al., 2008; Pauly et al., 2009b).

The jellyfish chronicles

The data used in this analysis were aggregated into "chronicles." Each chronicle consists of one or more pieces of evidence and has an associated "Abundance Trend" and "Confidence Index," calculated from scores for spatial and temporal extent, as well as reliability. The reliability score allowed us to consider and combine information from the scientific, peer-reviewed literature, as well as information gleaned from other sources (e.g., "anecdotes"). These chronicles were aggregated by LME and then analyzed using a fuzzy logic expert system (Zadeh, 1965) to generate a "Jellyfish Index" for each LME. 
Multiple pieces of evidence covering similar temporal and spatial scales were included as one chronicle, and only data that referred to changes (or lack thereof) over several years or greater were included. Therefore, isolated references to "lots of jellyfish" or "more jellyfish than last year" would not qualify for inclusion due to low temporal coverage. The same rationale was applied to populations with decreasing or relatively stable trends, or those showing high variability.

Increasing or decreasing trends were reported to occur only if they were sustained. Thus, a population of jellyfish showing a prolonged increase followed by a similar decrease was classified as "variable." Because chronicles were scored on several components, those with no recent data (post-2000) received a lower temporal score in order to reflect the uncertainty of whether the identified trend has continued or not. Data for the North Sea LME chronicles were included here as an example. Details of all chronicles are in Brotz (2011).

\section{Data selection}

All direct comments or measurements indicating changes (or lack thereof) in jellyfish populations over several years were included in the analysis; however, indirect evidence was not included. Such indirect evidence consists of impacts of jellyfish on human activities such as sting events, clogging of intake pipes for power generation, shipping, or mining operations, as well as interference with aquaculture operations. Although changes in the frequency of these events may indicate changes in jellyfish populations (Purcell et al., 2007), there can also be a consequence of changes in sampling effort. For example, a jellyfish bloom that interferes with an industrial operation may actually represent a stable jellyfish population if the industrial operation is new to the region, rather than an actual increase in jellyfish. Therefore, isolated interference events with industrial operations were excluded from the analysis.

Individual events related to direct interference with fishing activities also were excluded. However, we included information that referred to the changing frequency of such events because we believed this to be a strong indication of a change in jellyfish abundance. For example, fishers in some locations reported increasing jellyfish by-catch over years or decades (e.g., Uye \& Ueta, 2004). Because fishers generally have a keen understanding of the marine environment, such statements were assumed to be reliable. In addition, for most locations with extant fisheries, it is expected that fishers have improved their ability to avoid catching jellyfish over time (e.g., Kendall, 1990; Matsushita \& Honda, 2006; Nagata et al., 2009). Thus, we believed that increases in jellyfish by-catch observed by fishers were likely to reflect increased jellyfish populations.

Sting data generally were not included in our analysis, because they are problematic due to a number of factors. First, an increase in the number of people participating in marine activities would increase encounter rates (Macrokanis et al., 2004). In addition, data showing an increase in sting events may simply be a reflection of increased reporting (Gershwin et al., 2010). As such, an increase in sting events may not necessarily represent an increase in the amount of jellyfish present. Conversely, awareness and educational campaigns, as well as the use of jellyfish deterrents or countermeasures, can result in a decrease in sting events without a concomitant reduction of the jellyfish population (Gershwin et al., 2010). Therefore, sting data were excluded from the analysis, except where they revealed temporal changes (e.g., increase in the stinger season) or spatial changes (e.g., increased distribution of jellyfish).

\section{Abundance Trend}

Each chronicle was assigned an "Abundance Trend" of increasing $(+1)$, decreasing $(-1)$, or stable/variable $(0)$. The trend was identified by considering changes in integrated biomass (i.e., abundance and presence). Therefore, increases (or decreases) in any metric (overall biomass, frequency of occurrence, or duration of occurrence) were considered to be indications of an increase (or decrease). As such, more frequent blooms, larger blooms, longer-lasting blooms, and range expansions (and their converses) all were included. When knowledge was available on multiple species over similar scales, the overall biomass of jellyfish within the ecosystem was considered. In addition, small, non-abundant hydromedusae received lower scores due to the fact that they are less likely to affect the overall biomass of jellyfish in the ecosystem.

Supporting evidence for each chronicle consisted of either qualitative or quantitative information. 
Chronicles with qualitative data as their primary source were classified based on the description of the jellyfish population in question (Table 1). For chronicles with quantitative records, such as multi-year datasets with values for relative abundance or biomass, a general linear regression analysis was performed. If the slope of the linear regression (abundance against time) was positive and significantly different from zero $(P<0.05)$, the dataset was considered to represent an increase. Conversely, a significant negative slope constituted a decrease. If the slope of the linear regression was not statistically significant, the dataset was classified as stable/ variable.

\section{Scoring the chronicles}

Each chronicle was scored according to a set of rules (Table 1) based on temporal coverage ("Time score"), spatial coverage ("Space score"), and reliability ("Reliability score") with the reliability for invasive species scored differently. These scores were used to calculate the overall "Confidence Index," a measure of the level of certainty for each chronicle.

\section{Invasive species}

Here, we consider invasive species to represent those that have been declared as non-indigenous by experts. The presence of invasive species of jellyfish was assumed to represent an increase in jellyfish biomass (Abundance Trend $=1$ ). With this assumption, it is clearly important to understand if an invasive species is truly established because some invaders can appear briefly in a particular area, but not be detected thereafter. Knowledge of such events was assumed to represent no change in a jellyfish population (Abundance Trend $=0$ ), rather than an increase, as the excess biomass due to the invader presumably vanishes if the species is no longer detected. However, the possibility of repeated detection persists due to potential establishment by cryptic polyps or successive invasions, as is likely with Phyllorhiza sp. in the South Brazil Shelf LME (Haddad \& Nogueira, 2006). The possibility also exists that invasive species of jellyfish could cause a reduction in native jellyfish biomass. However, no evidence of such an event was found (but see Brotz, 2011 for discussion).
Chronicles that pertained to invasive species were scored similarly to other chronicles on the basis of time and space, but differently for reliability. The contribution to an increase in jellyfish biomass due to an invader was weighted by the "Invasive reliability score" (Table 1) to provide a more accurate estimate of the total change in jellyfish biomass. The assumptions and weighting factors were designed to avoid an overemphasis on invasive species. However, the invasive jellyfish accounted for in this analysis represent a conservative estimate, because it is likely that far more invasions have occurred than have been documented due to incomplete treatment, unusual life histories, and species crypsis (Holland et al., 2004; Dawson et al., 2005; Graham \& Bayha, 2007). Invasive species were treated separately during analyses, allowing assessment of their contribution to the results. Consistent with the baseline selected for the analysis, species that invaded regions prior to 1950 were excluded.

\section{Fuzzy logic expert system}

Scores and chronicles were combined using a series of rule sets and fuzzy logic. The steps are outlined below, and the methodology diagramed using the North Sea LME as an example (Fig. 1). Fuzzy set theory, originally developed by Zadeh (1965), is now firmly established in engineering and science (e.g., Lee, 1990; van der Werf \& Zimmer, 1998; Cheung et al., 2007), and fuzzy models are increasingly being used for ecological applications (Jørgensen, 2008). Fuzzy set theory allows the representation of variables according to a gradation or degree of membership, rather than the classic "true" or "false" membership of conventional Boolean sets. In addition, fuzzy logic allows a conclusion to be reached with an associated gradation or degree of belief. As such, fuzzy set theory and logic provide an ideal system for combining information of variable cardinality and confidence. Adriaenssens et al. (2004) reviewed fuzzy set theory used in ecosystem studies and Brotz (2011) details the specific methodology used in our study.

Variables with differing degrees of confidence were combined using the "MYCIN" method, an asymptotic accumulation of the degree of belief, after Buchanan \& Shortliffe (1984). This knowledge accumulation method is not affected by the order in which evidence is combined, and can be defined as: 
Table 1 Rule sets defined for analysis of jellyfish population trends in LME

Definition

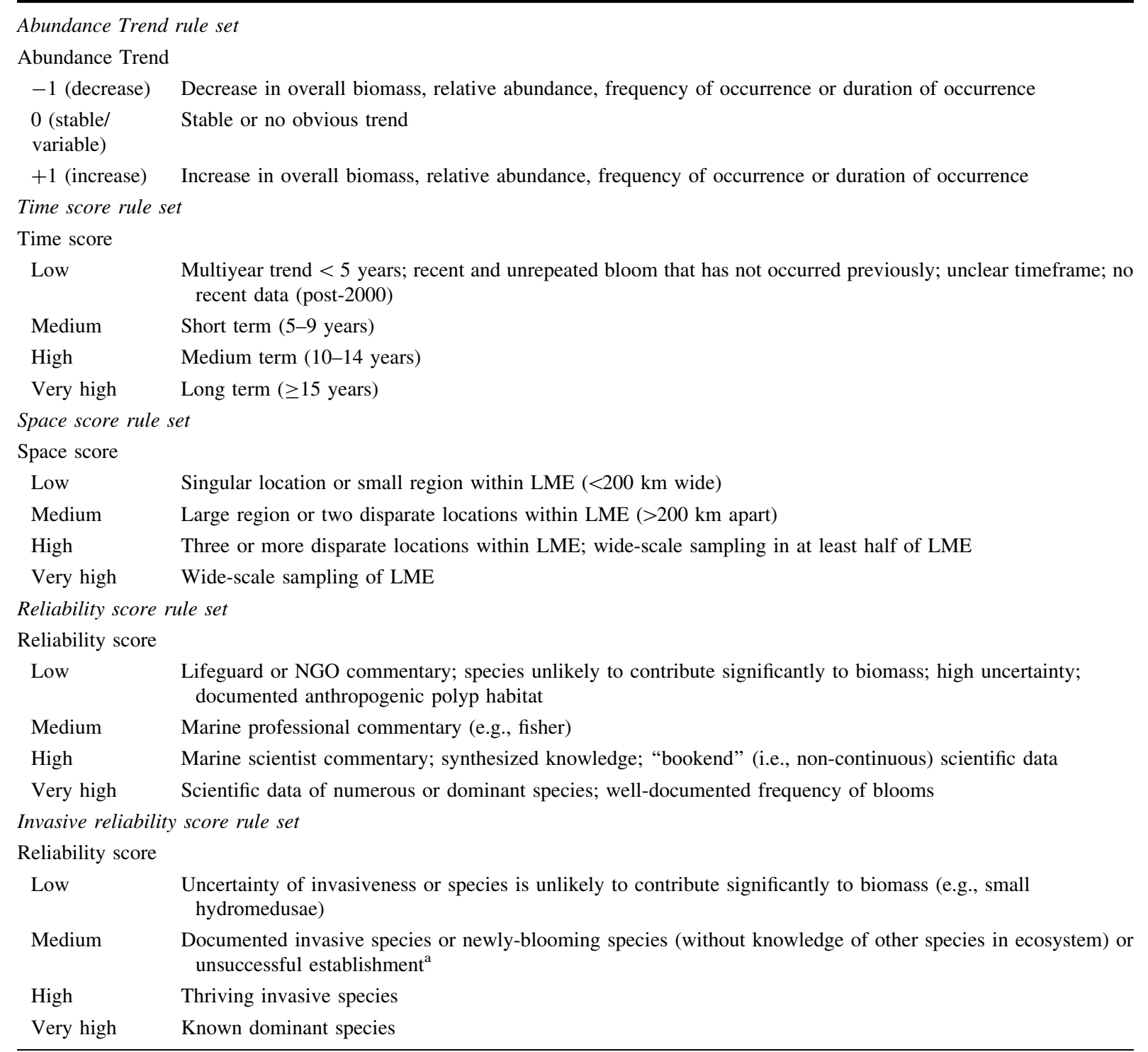

Rule sets here include: Abundance Trend, Time score, Space score, and Reliability scores for native and invasive species. Additional parameters are in Tables 2 and 3

a Abundance Trend $=1$ in all invasive cases except for unsuccessful establishment (where Abundance Trend $=0$ and Invasive reliability score $=$ medium)

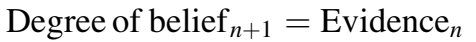

$$
\begin{aligned}
& +\left[\left(1-\text { Evidence }_{n}\right) \times \text { Evidence }_{n+1}\right]
\end{aligned}
$$

where Degree of belief ${ }_{n+1}$ is the membership in the conclusion after combining the membership from Evidence $_{n}$ and Evidence ${ }_{n+1}$. The membership for any number of pieces of evidence can thus be combined to yield a final membership (i.e., degree of belief) in the conclusion.

The three scores for each jellyfish chronicle (time, space, and reliability) were combined using a fuzzy rule set, or combination matrix, to yield a "Confidence Index" (Table 2). The combination matrix used treats all three scores equally, and therefore represents all 


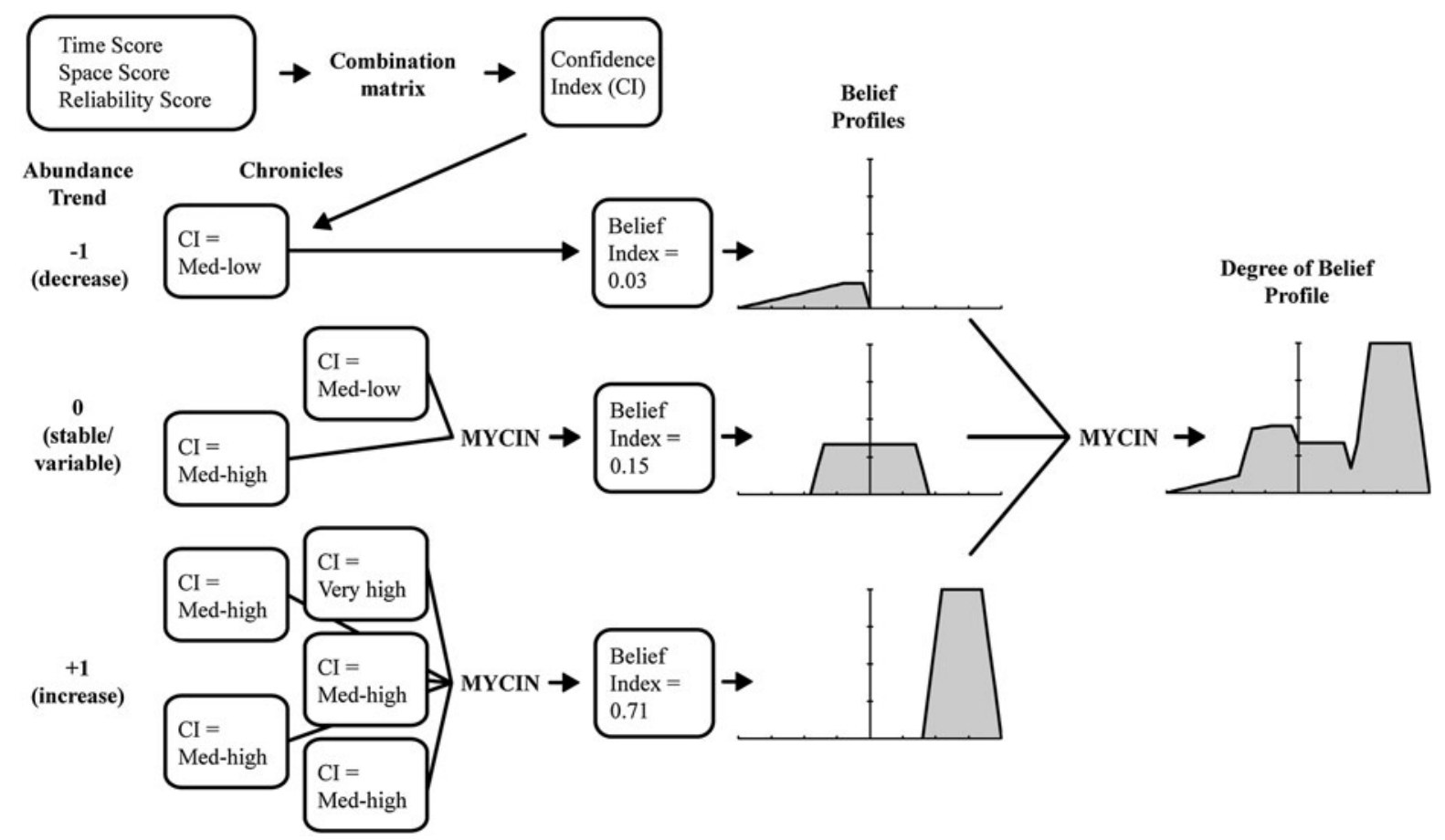

Fig. 1 Schematic diagram of the fuzzy expert system used in the analysis of jellyfish population trends by LME, with the North Sea LME represented as an example

possible combinations of scores. Thus, each chronicle has an associated Abundance Trend representing the direction of change for the jellyfish population in question and a Confidence Index representing the Degree of Belief. Chronicles included in the North Sea LME (Table 3) are depicted in the fuzzy expert system diagram (Fig. 1). Details of all chronicles used in this analysis are in Brotz (2011).

Within each LME, chronicles that had the same Abundance Trend were combined to yield a Belief Index, which was derived by converting the Confidence Index value for each chronicle into a membership (Degree of Belief; Table 4) and subsequently combining these memberships using MYCIN. The resulting Belief Indexes for each Abundance Trend were used to select an appropriate Belief Profile (Table 4). The Belief Profiles used in the fuzzy expert system were membership functions designed to represent the Degree of Belief over a continuous scale of -100 to +100 , with negative scores representing declining jellyfish populations and positive scores representing increasing populations. These asymmetrical Belief Profiles therefore provide a representation of the accumulated evidence for each particular trend, including both the quantity and the relative certainty of the evidence. Within each LME, one profile was selected for each Abundance Trend, as long as there was supporting evidence (i.e., Belief Index $>0$ ). Thus, an LME could have 1, 2, or 3 profiles as inputs for the fuzzy expert system, depending on whether or not there were chronicles supporting each Abundance Trend. The Belief Profiles were combined using the MYCIN method to yield a final Degree of Belief profile for each LME. This profile contained information about the evidence within each LME over all Abundance Trends. To calculate a final Jellyfish Index, the centroid-weighted method (Cox, 1999) was used to "defuzzify" the final profile.

\section{Uncertainty}

The confidence in the Jellyfish Index was quantified by the Degree of Belief at the centroid value (the "Confidence Factor") and the associated values at Degree of Belief $=0.25$ (the confidence limits). The difference between the confidence limits is defined as the "Confidence Interval." If a particular profile did not reach a Degree of Belief $=0.25$ due to lack of 
Table 2 Combination matrix used to combine scores, yielding a single Confidence Index

\begin{tabular}{|c|c|c|c|}
\hline Score A & Score B & Score C & Confidence Index \\
\hline Low & Low & Low & Low \\
\hline Low & Low & Medium & Low \\
\hline Low & Low & High & Medium-low \\
\hline Low & Low & Very high & Medium-low \\
\hline Low & Medium & Medium & Medium-low \\
\hline Low & Medium & High & Medium \\
\hline Low & Medium & Very high & Medium \\
\hline Low & High & High & Medium \\
\hline Low & High & Very high & Medium-high \\
\hline Low & Very high & Very high & Medium-high \\
\hline Medium & Medium & Medium & Medium \\
\hline Medium & Medium & High & Medium-high \\
\hline Medium & Medium & Very high & Medium-high \\
\hline Medium & High & High & Medium-high \\
\hline Medium & High & Very high & High \\
\hline Medium & Very high & Very high & High \\
\hline High & High & High & High \\
\hline High & High & Very high & High \\
\hline High & Very high & Very high & Very high \\
\hline Very high & Very high & Very high & Very high \\
\hline
\end{tabular}

Scores for time, space, and reliability were treated equally, and therefore the matrix represents all possible combinations of scores

evidence (e.g., Gulf of California LME), the upper and lower confidence limits were selected where the Degree of Belief falls to zero. Use of these two measures of uncertainty (the Confidence Factor and the Confidence Interval) provided information about both the strength of the data within an LME and how consistent was the observed trend (if any). These would be similar to measures of "accuracy" and "precision," i.e., a high Confidence Factor represented a robust conclusion and could be interpreted as accurate. Similarly, a small Confidence Interval would indicate that the chronicles included in a particular LME have comparable trends and were therefore precise. The combination of these two measures ultimately defined the overall confidence in the Jellyfish Index for each LME; thus, we defined a "Confidence Quotient" as equal to the Confidence Factor divided by the Confidence Interval. Conclusions with a Confidence Quotient $>1$ were classified as "high certainty," while those with a Confidence Quotient $<1$ were classified as "low certainty."
Based on the Belief Profiles used in the analysis, Jellyfish Indexes could range from a minimum of -70 to a maximum of +70 . LMEs with a Jellyfish Index of greater than +10 were classified as increases, while those with a Jellyfish Index less than -10 were classified as decreases. LMEs with a Jellyfish Index between -10 and +10 were classified as stable/ variable, indicating they did not show an increasing or decreasing trend. These thresholds were chosen in order to ensure there was sufficient evidence to suggest a trend.

\section{Results}

A total of 138 jellyfish chronicles were included in the analysis, distributed unevenly over 45 LMEs. Results including both native and invasive species are presented in Table 5. Of the 45 LMEs, 28 (62\%) showed increasing trends, while only $3(7 \%)$ showed decreasing trends. The remaining 14 LMEs (31\%) were classified as stable/variable, showing neither increasing nor decreasing trends (Fig. 2).

Out of the 28 LMEs exhibiting increases, 10 were classified as high certainty (Confidence Quotient $>1$ ) and 18 as low certainty. Of the 14 LMEs with stable/ variable trends, 4 were of high certainty and 10 were of low certainty. The Humboldt Current LME was the only system to exhibit a decrease associated with a high certainty.

The results are similar when normalized by area of the LMEs; $21 \%$ of the total area included represented regions with increases of high certainty, while increases of low certainty represented $45 \%$. Stable/ variable regions represented $28 \%$ of the total area included, while the remaining $6 \%$ was associated with decreases.

\section{Effects of invasive species}

Invasive species were separated from the analysis to examine their effects on the results (Tables 5, 6). Invasive species of jellyfish were reported in 21 LMEs. In eight of those, the inclusion of invasive species had a negligible contribution to the results and did not affect the Jellyfish Index. By contrast, the inclusion of invasive species was responsible for the conclusion of low certainty increases in four LMEs (Gulf of Mexico, Southeast U.S. Continental Shelf, 


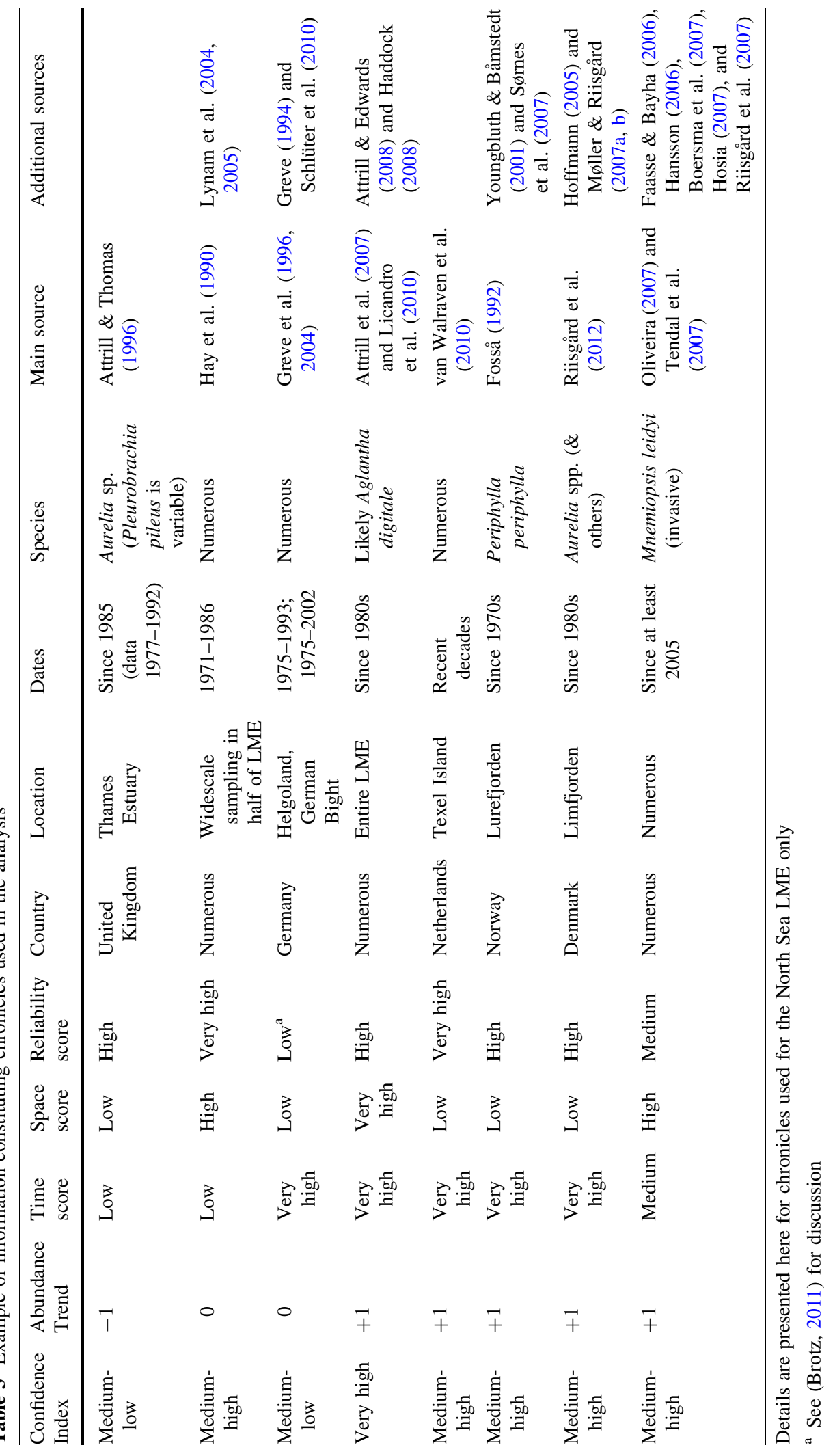


Table 4 Rule sets used in the fuzzification process of the fuzzy expert system

\begin{tabular}{ll}
\hline Confidence Index & $\begin{array}{l}\text { Degree of Belief } \\
\text { (per chronicle) }\end{array}$ \\
\hline Low & 0.0156 \\
Medium-low & 0.0313 \\
Medium & 0.0625 \\
Medium-high & 0.125 \\
High & 0.25 \\
Very high & 0.5 \\
\hline Belief Index & Belief Profile \\
\hline 0 & None \\
$0.01-0.09$ & Low \\
$0.1-0.19$ & Medium-low \\
$0.2-0.34$ & Medium \\
$0.35-0.49$ & Medium-high \\
$0.50-0.59$ & High \\
$0.60-1$ & Very high \\
\hline
\end{tabular}

Rule sets here include the Degree of Belief membership according to the Confidence Index for each chronicle and the Belief Profile selection according to the Belief Index. See text and Fig. 1 for additional information

Caribbean Sea, and Baltic Sea), because the exclusion of invaders changed the classification of these LMEs from increasing to stable/variable. Similarly, invaders were responsible for the low certainty increase in the East Brazil Shelf LME because there were no data for native species. The Insular Pacific-Hawaiian LME exhibited an increase due to native species; however, the inclusion of invasive species increased the certainty of the conclusion to high. In the remaining LMEs, the inclusion of invasive species increased the Jellyfish Index by variable amounts, but did not alter the conclusions.

Considering the effects of jellyfish overexploitation

Interestingly, several of the chronicles that were classified as decreases in the analysis (Abundance Trend $=-1$ ) concerned jellyfish species that have been harvested for food, science, or unique proteins, and have subsequently declined, possibly as a result of overfishing. Only four chronicles had a primary source of evidence that directly attributed a decrease to overexploitation; therefore, these chronicles were treated separately in the analysis. In the Arabian Sea LME, the inclusion of overfishing of jellyfish reduced the Jellyfish Index sufficiently to alter the trend conclusion from increasing to stable/variable (both conclusions of low certainty). Inclusion of overfishing of jellyfish for the Bay of Bengal LME resulted in no change to the Jellyfish Index. The South China Sea and East Central Australian Shelf LMEs showed a reduced Jellyfish Index when overfishing of jellyfish was included; however, this reduction was not sufficient to classify these LMEs as decreases and they remained classified as stable/variable. Thus, in the majority of locations where overfishing of jellyfish could be identified, it did not alter the conclusions of the analysis.

\section{Discussion}

This study represents the first rigorous demonstration that jellyfish populations appear to be increasing in coastal ecosystems worldwide, as previously suggested (Mills, 2001; Purcell et al., 2007; Pauly et al., 2009a; Richardson et al., 2009). Of the 45 LMEs included in our analysis, 28 (62\%) showed increasing trends, while only 3 (7\%) showed decreasing trends. The remaining 14 LMEs (31\%) were classified as stable/variable, with no obvious trend. These results suggest that while increases of jellyfish populations are not universal, they are both numerous and widespread. Of the 21 LMEs that were not included in our analysis, most were from the Arctic (11), Australia (4), and the South Pacific (3). Therefore, our results represent extensive spatial coverage of the world's coastal ecosystems. While only $33 \%$ of the conclusions are of high certainty, the majority of those (10 of 15) were in LMEs that showed increasing trends. In addition to demonstrating that jellyfish populations have increased in numerous ecosystems around the world, our analysis also underscored the fact that information on jellyfish abundance is poor over much of the globe. Thus, we must strive to learn more about these important creatures, especially given the fact that they seem to be one of the few groups of organisms that may benefit from the continued anthropogenic impacts on the world's biosphere.

Defining an "increase"

Information used in the analysis was weighted by time, space, and reliability to reflect the relative contribution 
Table 5 Results of analysis of jellyfish population trends by LME including both native and invasive species

\begin{tabular}{|c|c|c|c|c|c|c|c|c|c|}
\hline $\begin{array}{l}\text { LME } \\
\text { ID }\end{array}$ & LME name & $\begin{array}{l}\text { Trend } \\
\text { conclusion }\end{array}$ & $\begin{array}{l}\text { Conclusion } \\
\text { certainty }\end{array}$ & $\begin{array}{l}\text { Jellyfish } \\
\text { Index }\end{array}$ & $\begin{array}{l}\text { Confidence } \\
\text { Quotient }\end{array}$ & $\begin{array}{l}\text { Confidence } \\
\text { Factor }\end{array}$ & $\begin{array}{l}\text { Lower } \\
\text { limit }\end{array}$ & $\begin{array}{l}\text { Upper } \\
\text { limit }\end{array}$ & Interval \\
\hline 1 & East Bering Sea & Increase & High & 61.84 & 1.47 & 0.83 & 34.50 & 91.00 & 56.50 \\
\hline 2 & Gulf of Alaska & $\begin{array}{l}\text { Stable/ } \\
\text { variable }\end{array}$ & Low & 7.06 & 0.80 & 0.58 & -35.00 & 37.24 & 72.24 \\
\hline 3 & California Current & Increase & Low & 25.55 & 0.63 & 0.73 & -31.25 & 85.00 & 116.25 \\
\hline 4 & Gulf of California & Increase & Low & 35.87 & 0.13 & 0.13 & 0.00 & 100.00 & 100.00 \\
\hline 5 & Gulf of Mexico & Increase & Low & 14.13 & 0.75 & 0.65 & -35.00 & 51.25 & 86.25 \\
\hline 6 & $\begin{array}{l}\text { Southeast US } \\
\text { Continental Shelf }\end{array}$ & Increase & Low & 14.13 & 0.75 & 0.65 & -35.00 & 51.25 & 86.25 \\
\hline 7 & $\begin{array}{l}\text { Northeast US } \\
\text { Continental Shelf }\end{array}$ & Increase & High & 52.52 & 1.58 & 0.83 & 43.75 & 96.25 & 52.50 \\
\hline 8 & Scotian Shelf & $\begin{array}{l}\text { Stable/ } \\
\text { variable }\end{array}$ & High & 0.00 & 1.07 & 0.67 & -31.25 & 31.25 & 62.50 \\
\hline 9 & $\begin{array}{l}\text { Newfoundland- } \\
\text { Labrador Shelf }\end{array}$ & $\begin{array}{l}\text { Stable/ } \\
\text { variable }\end{array}$ & High & 0.00 & 1.54 & 0.83 & -27.00 & 27.00 & 54.00 \\
\hline 10 & $\begin{array}{l}\text { Insular Pacific- } \\
\text { Hawaiian }\end{array}$ & Increase & High & 54.84 & 1.13 & 0.67 & 25.63 & 85.00 & 59.37 \\
\hline 11 & $\begin{array}{l}\text { Pacific Central- } \\
\text { American Coastal }\end{array}$ & Increase & Low & 41.74 & 0.77 & 0.30 & 12.50 & 51.25 & 38.75 \\
\hline 12 & Caribbean Sea & Increase & Low & 13.60 & 0.81 & 0.31 & 3.00 & 41.26 & 38.26 \\
\hline 13 & Humboldt Current & Decrease & High & -42.80 & 1.26 & 0.71 & -91.00 & -34.50 & 56.50 \\
\hline 14 & Patagonian Shelf & Increase & Low & 47.90 & 0.87 & 0.50 & 17.50 & 75.00 & 57.50 \\
\hline 15 & South Brazil Shelf & $\begin{array}{l}\text { Stable/ } \\
\text { variable }\end{array}$ & Low & 7.06 & 0.80 & 0.58 & -35.00 & 37.24 & 72.24 \\
\hline 16 & East Brazil Shelf & Increase & Low & 35.87 & 0.13 & 0.13 & 0.00 & 100.00 & 100.00 \\
\hline 18 & $\begin{array}{l}\text { West Greenland } \\
\text { Shelf }\end{array}$ & Decrease & Low & -35.87 & 0.13 & 0.13 & -100.00 & 0.00 & 100.00 \\
\hline 21 & Norwegian Sea & Increase & Low & 41.74 & 0.70 & 0.27 & 12.50 & 51.25 & 38.75 \\
\hline 22 & North Sea & Increase & Low & 35.89 & 0.22 & 0.30 & -40.67 & 96.25 & 136.92 \\
\hline 23 & Baltic Sea & Increase & Low & 14.13 & 0.75 & 0.65 & -35.00 & 51.25 & 86.25 \\
\hline 24 & Celtic-Biscay Shelf & Increase & Low & 36.94 & 0.44 & 0.56 & -37.50 & 91.00 & 128.50 \\
\hline 25 & Iberian Coastal & $\begin{array}{l}\text { Stable/ } \\
\text { variable }\end{array}$ & Low & 7.06 & 0.80 & 0.58 & -35.00 & 37.24 & 72.24 \\
\hline 26 & Mediterranean Sea & Increase & Low & 43.95 & 0.22 & 0.30 & -37.50 & 96.25 & 133.75 \\
\hline 28 & Guinea Current & Increase & Low & 35.87 & 0.13 & 0.13 & 0.00 & 100.00 & 100.00 \\
\hline 29 & Benguela Current & Increase & High & 54.84 & 1.15 & 0.67 & 26.63 & 85.00 & 58.37 \\
\hline 30 & Agulhas Current & $\begin{array}{l}\text { Stable/ } \\
\text { variable }\end{array}$ & Low & 0.00 & 0.71 & 0.50 & -35.00 & 35.00 & 70.00 \\
\hline 31 & $\begin{array}{l}\text { Somali Coastal } \\
\text { Current }\end{array}$ & $\begin{array}{l}\text { Stable/ } \\
\text { variable }\end{array}$ & Low & 0.00 & 0.44 & 0.33 & -37.50 & 37.50 & 75.00 \\
\hline 32 & Arabian Sea & Increase & Low & 14.13 & 0.75 & 0.65 & -35.00 & 51.25 & 86.25 \\
\hline 34 & Bay of Bengal & Increase & Low & 14.57 & 0.52 & 0.58 & -37.24 & 75.00 & 112.24 \\
\hline 35 & Gulf of Thailand & Increase & Low & 35.87 & 0.13 & 0.13 & 0.00 & 100.00 & 100.00 \\
\hline 36 & South China Sea & $\begin{array}{l}\text { Stable/ } \\
\text { variable }\end{array}$ & Low & 8.86 & 0.56 & 0.44 & -37.50 & 40.67 & 78.17 \\
\hline 40 & $\begin{array}{l}\text { Northeast Australian } \\
\text { Shelf }\end{array}$ & Increase & Low & 35.87 & 0.13 & 0.13 & 0.00 & 100.00 & 100.00 \\
\hline
\end{tabular}


Table 5 continued

\begin{tabular}{|c|c|c|c|c|c|c|c|c|c|}
\hline $\begin{array}{l}\text { LME } \\
\text { ID }\end{array}$ & LME name & $\begin{array}{l}\text { Trend } \\
\text { conclusion }\end{array}$ & $\begin{array}{l}\text { Conclusion } \\
\text { certainty }\end{array}$ & $\begin{array}{l}\text { Jellyfish } \\
\text { Index }\end{array}$ & $\begin{array}{l}\text { Confidence } \\
\text { Quotient }\end{array}$ & $\begin{array}{l}\text { Confidence } \\
\text { Factor }\end{array}$ & $\begin{array}{l}\text { Lower } \\
\text { limit }\end{array}$ & $\begin{array}{l}\text { Upper } \\
\text { limit }\end{array}$ & Interval \\
\hline 41 & $\begin{array}{l}\text { East Central } \\
\text { Australian Shelf }\end{array}$ & $\begin{array}{l}\text { Stable/ } \\
\text { variable }\end{array}$ & Low & 0.00 & 0.71 & 0.50 & -35.00 & 35.00 & 70.00 \\
\hline 42 & $\begin{array}{l}\text { Southeast Australian } \\
\text { Shelf }\end{array}$ & $\begin{array}{l}\text { Stable/ } \\
\text { variable }\end{array}$ & Low & 8.86 & 0.56 & 0.44 & -37.50 & 40.67 & 78.17 \\
\hline 47 & East China Sea & Increase & High & 70.00 & 1.90 & 1.00 & 43.75 & 96.25 & 52.50 \\
\hline 48 & Yellow Sea & Increase & High & 61.84 & 1.47 & 0.83 & 34.50 & 91.00 & 56.50 \\
\hline 49 & Kuroshio Current & Increase & High & 35.34 & 1.13 & 0.67 & 25.63 & 85.00 & 59.37 \\
\hline 50 & Sea of Japan & Increase & High & 61.84 & 1.47 & 0.83 & 34.50 & 91.00 & 56.50 \\
\hline 51 & Oyashio Current & Decrease & Low & -14.13 & 0.75 & 0.65 & -51.25 & 35.00 & 86.25 \\
\hline 52 & Sea of Okhotsk & $\begin{array}{l}\text { Stable/ } \\
\text { variable }\end{array}$ & High & 6.25 & 1.55 & 0.86 & -27.00 & 28.56 & 55.56 \\
\hline 53 & West Bering Sea & $\begin{array}{l}\text { Stable/ } \\
\text { variable }\end{array}$ & Low & -7.49 & 0.40 & 0.50 & -75.00 & 51.25 & 125.25 \\
\hline 60 & Faroe Plateau & $\begin{array}{l}\text { Stable/ } \\
\text { variable }\end{array}$ & High & 0.00 & 1.54 & 0.83 & -27.00 & 27.00 & 54.00 \\
\hline 61 & Antarctic & Increase & High & 61.84 & 1.47 & 0.83 & 34.50 & 91.00 & 56.50 \\
\hline 62 & Black Sea & Increase & High & 70.00 & 1.90 & 1.00 & 43.75 & 96.25 & 52.50 \\
\hline 63 & Hudson Bay & $\begin{array}{l}\text { Stable/ } \\
\text { variable }\end{array}$ & Low & 0.00 & 0.44 & 0.33 & -37.50 & 37.50 & 75.00 \\
\hline
\end{tabular}

to a change in jellyfish populations within each LME. As a consequence of the methods used and the inclusion of anecdotal data, the results reflect the degree of belief that any particular jellyfish population has changed or not, rather than the magnitude of those changes. Therefore, observations of "more" jellyfish

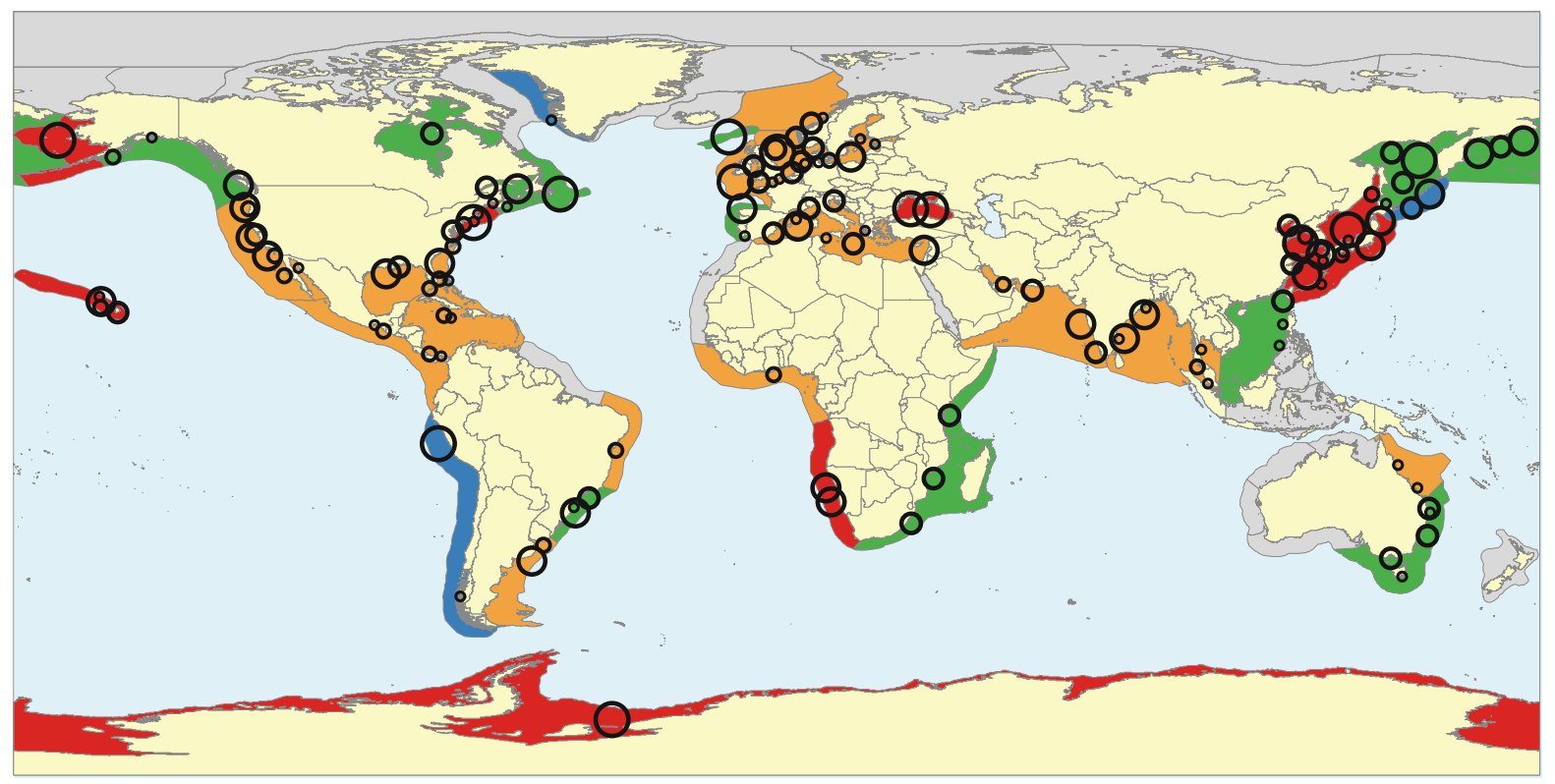

Fig. 2 Map of population trends of native and invasive species of jellyfish by LME. Red increase (high certainty), orange increase (low certainty), green stable/variable, blue decrease, grey no data. Circles represent discrete chronicles with relative sizes reflecting the Confidence Index. Circle locations are approximate, as some were shifted to avoid overlap; the circle for the Antarctic LME summarizes circumpolar observations 
Table 6 Results of analysis of jellyfish population trends by LME including native species only (effects of invasive species excluded; only those LMEs that had invasive species are shown)

\begin{tabular}{|c|c|c|c|c|c|c|c|c|c|}
\hline $\begin{array}{l}\text { LME } \\
\text { ID }\end{array}$ & LME name & $\begin{array}{l}\text { Trend } \\
\text { conclusion }\end{array}$ & $\begin{array}{l}\text { Conclusion } \\
\text { certainty }\end{array}$ & $\begin{array}{l}\text { Jellyfish } \\
\text { Index }\end{array}$ & $\begin{array}{l}\text { Confidence } \\
\text { Quotient }\end{array}$ & $\begin{array}{l}\text { Confidence } \\
\text { Factor }\end{array}$ & $\begin{array}{l}\text { Lower } \\
\text { limit }\end{array}$ & $\begin{array}{l}\text { Upper } \\
\text { limit }\end{array}$ & Interval \\
\hline 3 & California Current & Increase & Low & 19.82 & 0.73 & 0.78 & -31.25 & 75.00 & 106.25 \\
\hline 5 & Gulf of Mexico & $\begin{array}{l}\text { Stable/ } \\
\text { variable }\end{array}$ & Low & 7.06 & 0.80 & 0.58 & -35.00 & 37.24 & 72.24 \\
\hline 6 & $\begin{array}{l}\text { Southeast US } \\
\text { Continental Shelf }\end{array}$ & $\begin{array}{l}\text { Stable/ } \\
\text { variable }\end{array}$ & Low & 7.06 & 0.80 & 0.58 & -35.00 & 37.24 & 72.24 \\
\hline 7 & $\begin{array}{l}\text { Northeast US } \\
\text { Continental Shelf }\end{array}$ & Increase & High & 52.52 & 1.58 & 0.83 & 43.75 & 96.25 & 52.50 \\
\hline 10 & $\begin{array}{l}\text { Insular Pacific- } \\
\text { Hawaiian }\end{array}$ & Increase & Low & 47.90 & 0.87 & 0.50 & 17.50 & 75.00 & 57.50 \\
\hline 11 & $\begin{array}{l}\text { Pacific Central- } \\
\text { American Coastal }\end{array}$ & Increase & Low & 35.87 & 0.09 & 0.09 & 0.00 & 100.00 & 100.00 \\
\hline 12 & Caribbean Sea & $\begin{array}{l}\text { Stable/ } \\
\text { variable }\end{array}$ & Low & 0.00 & 0.17 & 0.17 & -50.00 & 50.00 & 100.00 \\
\hline 13 & Humboldt Current & Decrease & High & -61.84 & 1.47 & 0.83 & -91.00 & -34.50 & 56.50 \\
\hline 14 & Patagonian Shelf & Increase & Low & 47.90 & 0.87 & 0.50 & 17.50 & 75.00 & 57.50 \\
\hline 15 & South Brazil Shelf & $\begin{array}{l}\text { Stable/ } \\
\text { variable }\end{array}$ & Low & 0.00 & 0.71 & 0.50 & -35.00 & 35.00 & 70.00 \\
\hline 16 & East Brazil Shelf & No data & & & & & & & \\
\hline 21 & Norwegian Sea & Increase & Low & 41.74 & 0.70 & 0.27 & 12.50 & 51.25 & 38.75 \\
\hline 22 & North Sea & Increase & Low & 35.89 & 0.22 & 0.30 & -40.67 & 96.25 & 136.92 \\
\hline 23 & Baltic Sea & $\begin{array}{l}\text { Stable/ } \\
\text { variable }\end{array}$ & Low & 0.00 & 0.71 & 0.50 & -35.00 & 35.00 & 70.00 \\
\hline 25 & Iberian Coastal & $\begin{array}{l}\text { Stable/ } \\
\text { variable }\end{array}$ & Low & 0.00 & 0.71 & 0.50 & -35.00 & 35.00 & 70.00 \\
\hline 26 & Mediterranean Sea & Increase & Low & 31.02 & 0.54 & 0.66 & -37.50 & 85.00 & 122.50 \\
\hline 42 & $\begin{array}{l}\text { Southeast Australian } \\
\text { Shelf }\end{array}$ & $\begin{array}{l}\text { Stable/ } \\
\text { variable }\end{array}$ & Low & 8.86 & 0.56 & 0.44 & -37.50 & 40.67 & 78.17 \\
\hline 47 & East China Sea & Increase & High & 70.00 & 1.90 & 1.00 & 43.75 & 96.25 & 52.50 \\
\hline 48 & Yellow Sea & Increase & High & 61.84 & 1.47 & 0.83 & 34.50 & 91.00 & 56.50 \\
\hline 49 & Kuroshio Current & Increase & High & 35.34 & 1.13 & 0.67 & 25.63 & 85.00 & 59.37 \\
\hline 62 & Black Sea & Increase & High & 61.84 & 1.47 & 0.83 & 34.50 & 91.00 & 56.50 \\
\hline
\end{tabular}

may not necessarily mean there were really "more jellyfish" if the observations were not normalized by effort. Nonetheless, we expected that these factors were correlated, as changes of larger magnitude were assumed to be more noticeable and thus have more supporting evidence. Only after accepting this assumption should this analysis be considered to reflect real "increases" and "decreases."

Jellyfish populations are extremely variable on both temporal and spatial scales, due to their peculiar ecology. Thus, even LMEs showing pronounced increases in jellyfish populations with "high certainty" may also experience dramatic declines over short timescales. For example, the trend in the East Bering Sea LME was classified as an increase based on a regression analysis, but jellyfish in the Bering Sea declined dramatically after 2000 (Brodeur et al., 2008). Despite this decline, jellyfish abundance in this LME appears sustained above the levels observed in the 1980s and the increase remains significant. Other long-term studies show similar variability, such as the 37-year dataset from Peru (Quiñones et al., 2010). Jellyfish populations in that system appear tightly correlated with El Niño events, but the data exhibited a decline (see Brotz, 2011). Even the welldocumented increase in blooms of the giant jellyfish 
(Nemopilema nomurai) in East Asia has not been persistent, because blooms have not occurred every year (Uye et al., 2010). Clearly then, increases or decreases may actually represent a trend during only part of a cycle, and may reverse over longer timeframes (Purcell, 2012).

With such high population variability, poor sampling frequency in either the past or present could dramatically affect the detection of true trends. To account for these concerns, attempts were made to ensure chronicles used in the analysis were of sufficient duration and up to date wherever possible. Therefore, chronicles covering longer timescales and those with up-to-date information had more influence on the results. Nonetheless, few datasets of jellyfish abundance span multiple decades; therefore, our results represent only a rough estimate of true jellyfish population dynamics. Moreover, the possibility of a reporting bias, whereby newsworthy blooms or increases of jellyfish were reported, but absences and stable or declining populations were not, could tend to overestimate increases. However, the methods used in our analysis were designed to minimize this effect. For instance, episodic blooms were not included unless a temporal component of at least several years was identified. In addition, as mentioned above, these temporal components were scored based on whether they represent recent trends and are of significant duration. Interference events with human activities, which are typically newsworthy, also were not included unless the information was in a clear historical context. Finally, much of the anecdotal information used in the analysis was gleaned from targeted interviews (e.g., Uye \& Ueta, 2004; Nagata et al., 2009; Pramod, 2010). Because numerous responses in those interviews indicated stable populations, they were assumed to represent a relatively unbiased source of information where scientific data were lacking.

The fact that jellyfish are typically part of the zooplankton makes them vulnerable to changes in oceanic current patterns. The presence or the absence of a bloom may simply be due to relocation; thus, an increase observed in one location may be concomitant with a decrease in another. If an increase is observed but a decrease is not, one may come to a false conclusion that jellyfish have increased. Whenever there was evidence of such an explanation, the chronicle was not included. An example is a recent quote from of a fisher in Florida who said he was seeing more sea nettles (Chrysaora sp.) now than in the preceding decades. However, this could be due to the relocation of the population normally observed elsewhere in the Gulf of Mexico (Spinner, 2010). Even without knowledge of such events, the analysis was not overly sensitive to that pitfall, because only multiyear data from the same location were used. As chronicles were either up-to-date or scored with low reliability, increases due to spatial redistributions would have to be sustained. In addition, chronicles based on information over short time periods or from single locations were also scored lower, thereby minimizing the effect on the results.

Possible causes of increasing jellyfish populations

Jellyfish have bloomed for hundreds of millions of years (Hagadorn et al., 2002; Young \& Hagadorn, 2010) and are a natural presence in healthy ecosystems. Many jellyfish populations are known to fluctuate with oceanic climate (reviews in Purcell, 2005, 2012). There are also suggestions that jellyfish may benefit from anthropogenic pressures on the marine environment (Mills, 1995; 2001; Purcell et al., 2007; Pauly et al., 2009a; Richardson et al., 2009, Purcell, 2012). Suggested causes include eutrophication, overfishing, global warming, habitat modification, aquaculture, salinity changes, ocean acidification, and of course, translocation.

Invasive species of jellyfish were reported in 21 of 45 LMEs in this analysis (47\% of the systems included). For the most part, invasive species were not responsible for the observed increases reflected in the results; however, the widespread detections demonstrate that jellyfish are truly global invaders of significant concern. Thriving populations of invasive jellyfish in systems like the Mediterranean and Black Seas should serve as warnings for other ecosystems around the globe, and it is likely that far more invasions have occurred than are reported (Holland et al., 2004; Dawson et al., 2005; Graham \& Bayha, 2007).

There is clearly no single cause of increasing jellyfish blooms. For example, populations of Aurelia sp. appear tightly correlated with aquaculture operations in Tapong Bay, Taiwan (Lo et al., 2008), whereas recent increased blooms of Aurelia sp. in Tokyo Bay, Japan are more likely due to the effects of eutrophication (Nomura \& Ishimaru, 1998; Ishii et al., 2008). In addition, possible causes may work in concert, synergistically creating conditions that benefit 
jellyfish (Purcell et al., 2007; Richardson et al., 2009; Pauly et al., 2009a; Purcell, 2012). Limited knowledge of jellyfish ecology, especially of benthic or sessile stages, inhibits our ability to draw conclusions regarding possible anthropogenic causes of jellyfish blooms. Nonetheless, the results of this analysis present a unique opportunity to examine commonalities using the LME framework. An important task will be to investigate possible linkages between anthropogenic stresses and increasing jellyfish populations as identified in this study.

\section{Taxonomic concerns}

The term "jellyfish," according the definition used here, refers to specimens from several phyla (Cnidaria, Ctenophora, and Chordata). Such organisms are obviously extremely distant phylogenetic relatives; therefore, grouping them under the umbrella term "jellyfish" is problematic. First, the use of such a term ignores taxonomy. The changes evident in the results of this analysis should not only be viewed in their entirety but also in the contexts of ecology and evolution. Without proper taxonomic resolution, a deeper and more meaningful understanding of the mechanisms and consequences involved may be unattainable (Haddock, 2004). Second, using a broad category also runs the risk of inferring attributes of a larger group of organisms based only on a handful of species. Such "errors of commission" (Dawson, 2010) could preclude robust conclusions if they are not made in the light of evolution. Generalizations concerning such a broad group of organisms will certainly have exceptions (Bayha \& Dawson, 2010), and we must be careful not to ignore these differences by focusing only on commonalities.

Despite these concerns, there is also value in generalized results. Notwithstanding their phylogenetic diversity, jellyfish share many similarities. If the increasing trends identified in this analysis are indeed caused by anthropogenic factors, raising awareness of the issues and developing a deeper understanding of the mechanisms involved should be priorities.

\section{Conclusions}

Jellyfish populations appear to be increasing in the majority of the world's coastal ecosystems and seas.
While these increases are conspicuous in several locations, even basic knowledge of jellyfish populations in most regions is poor. Many of the observed increases appear linked to human activities, but the mechanisms involved remain poorly understood. Because jellyfish populations can have important impacts on human activities and marine ecosystems, it is of paramount importance that we rapidly increase our understanding of these creatures.

Acknowledgments We thank the numerous scientists and marine professionals around the globe who kindly donated their knowledge and opinions of jellyfish populations. We also thank two anonymous reviewers and the guest editors of this volume whose comments improved the manuscript. This is a contribution from the Sea Around Us Project, a collaboration between the University of British Columbia's Fisheries Centre and the Pew Environment Group.

Open Access This article is distributed under the terms of the Creative Commons Attribution License which permits any use, distribution, and reproduction in any medium, provided the original author(s) and the source are credited.

\section{References}

Adriaenssens, V., B. D. Baets, P. L. M. Goethals \& N. D. Pauw, 2004. Fuzzy rule-based models for decision support in ecosystem management. Science of the Total Environment 319: 1-12.

Alldredge, A. L. \& L. P. Madin, 1982. Pelagic tunicates unique herbivores in the marine plankton. BioScience 32: 655-663.

Arai, M. N., 1997. A Functional Biology of Scyphozoa. Chapman and Hall, London: 300 pp.

Arai, M. N., 2009. The potential importance of podocysts to the formation of scyphozoan blooms: a review. Hydrobiologia 616: 241-246.

Atkinson, A., V. Siegel, E. Pakhomov \& P. Rothery, 2004. Long-term decline in krill stock and increase in salps within the Southern Ocean. Nature 432: 100-103.

Attrill, M. J. \& M. Edwards, 2008. Reply to Haddock, S. H. D. Reconsidering evidence for potential climate-related increases in jellyfish. Limnology and Oceanography 53: 2763-2766.

Attrill, M. J. \& R. M. Thomas, 1996. Long-term distribution patterns of mobile estuarine invertebrates (Ctenophora, Cnidaria, Crustacea: Decapoda) in relation to hydrological parameters. Marine Ecology Progress Series 143: 25-36.

Attrill, M. J., J. Wright \& M. Edwards, 2007. Climate-related increases in jellyfish frequency suggest a more gelatinous future for the North Sea. Limnology and Oceanography 52: 480-485.

Bayha, K. M. \& M. D. Dawson, 2010. New family of allomorphic jellyfishes, Drymonematidae, emphasizes evolution in the 
functional morphology and trophic ecology of gelatinous zooplankton. Biological Bulletin 219: 249-267.

Boero, F., J. Bouillon, C. Gravili, M. P. Miglietta, T. Parsons \& S. Piraino, 2008. Gelatinous plankton: irregularities rule the world (sometimes). Marine Ecology Progress Series 356: 299-310.

Boersma, M., A. M. Malzahn, W. Greve \& J. Javidpour, 2007. The first occurrence of the ctenophore Mnemiopsis leidyi in the North Sea. Helgoland Marine Research 61: 153-155.

Brodeur, R. D., M. B. Decker, L. Ciannelli, J. E. Purcell, N. A. Bond, P. J. Stabeno, E. Acuna \& G. L. Hunt, 2008. Rise and fall of jellyfish in the eastern Bering Sea in relation to climate regime shifts. Progress in Oceanography 77: 103-111.

Brotz, L., 2011. Changing jellyfish populations: trends in Large Marine Ecosystems. Fisheries Centre Research Report 19(5), Fisheries Centre, University of British Columbia, Vancouver.

Buchanan, B. G. \& E. H. Shortliffe (eds), 1984. Rule-Based Expert Systems - The MYCIN Experiments of the Stanford Heurisitic Programming Project. Addison-Wesley, Menlo Park.

Cheung, W. W. L., R. Watson, T. Morato, T. J. Pitcher \& D. Pauly, 2007. Intrinsic vulnerability in the global fish catch. Marine Ecology Progress Series 333: 1-12.

Chudnow, R., 2008. Are jellyfish populations increasing worldwide (and why)? Honours Bachelor's Thesis, Dalhousie University, Halifax.

Coleman, R., 2010. Jellyfish, fluorescent proteins, Nobel Prizes and pioneers in histochemistry. Acta Histochemica 112: 113-117.

Cox, E., 1999. The Fuzzy Systems Handbook: A Practitioner's Guide to Building, Using, and Maintaining Fuzzy Systems. AP Professional, San Diego.

Dawson, M., 2010. Cryptic ecology. Presentation, Third International Jellyfish Blooms Symposium, Mar del Plata, July 16, 2010.

Dawson, M. N. \& W. M. Hamner, 2009. A character-based analysis of the evolution of jellyfish blooms: adaptation and exaptation. Hydrobiologia 616: 193-215.

Dawson, M. N., A. Sen Gupta \& M. H. England, 2005. Coupled biophysical global ocean model and molecular genetic analyses identify multiple introductions of cryptogenic species. Proceedings of the National Academy of Sciences of the United States of America 102: 11968-11973.

Dovel, W. L., 1964. An approach to sampling estuarine macroplankton. Chesapeake Science 5: 77-90.

Faasse, M. A. \& K. M. Bayha, 2006. The ctenophore Mnemiopsis leidyi in coastal waters of the Netherlands: an unrecognized invasion? Aquatic Invasions 1: 270-277.

Fosså, J. H., 1992. Mass occurrence of Periphylla periphylla in a Norwegian fjord. Sarsia 77: 237-251.

Gershwin, L. A., M. De Nardi, K. D. Winkel \& P. J. Fenner, 2010. Marine stingers: review of an under-recognized global coastal management issue. Coastal Management 38: 22-41.

Graham, W. M. \& K. M. Bayha, 2007. Biological invasions by marine jellyfish. In Nentwig, W. (ed.), Biological Invasions. Ecological Studies, Vol. 193. Springer, Berlin: 239-255.

Greve, W., 1994. The 1989 German invasion of Muggiaea atlantica. ICES Journal of Marine Science 51: 355-358.

Greve, W., F. Reiners \& J. Nast, 1996. Biocoenotic changes of the zooplankton in the German Bight: the possible effects of eutrophication and climate. ICES Journal of Marine Science 53: 951-956.

Greve, W., F. Reiners, J. Nast \& S. Hoffmann, 2004. Helgoland Roads meso- and macrozooplankton time-series 1974 to 2004: lessons from 30 years of single spot, high frequency sampling at the only off-shore island of the North Sea. Helgoland Marine Research 58: 274-288.

Haddad, M. A. \& M. Nogueira, 2006. Reappearance and seasonality of Phyllorhiza punctata medusae in southern Brazil. Revista Brasileira De Zoologia 23: 824-831.

Haddock, S. H. D., 2004. A golden age of gelata: past and future research on planktonic ctenophores and cnidarians. Hydrobiologia 530: 549-556.

Haddock, S. H. D., 2008. Reconsidering evidence for potential climate-related increases in jellyfish. Limnology and Oceanography 53: 2759-2762.

Hagadorn, J. W., R. H. Dott \& D. Damrow, 2002. Stranded on a late Cambrian shoreline: medusae from central Wisconsin. Geology 30: 147-150.

Hamner, W. M. \& M. N. Dawson, 2009. A review and synthesis on the systematics and evolution of jellyfish blooms: advantageous aggregations and adaptive assemblages. Hydrobiologia 616: 161-191.

Hansson, H. G., 2006. Ctenophores of the Baltic and adjacent Seas - the invader Mnemiopsis is here! Aquatic Invasions 1: 295-298.

Hay, S., 2006. Marine ecology: gelatinous bells may ring change in marine ecosystems. Current Biology 16: R679-R682.

Hay, S. J., J. R. G. Hislop \& A. M. Shanks, 1990. North Sea scyphomedusae - summer distribution, estimated biomass and significance particularly for 0-group Gadoid fish. Netherlands Journal of Sea Research 25: 113-130.

Heinle, D. R., 1965. A screen for excluding jellyfish and ctenophores from Clarke-Bumpus plankton samples. Chesapeake Science 6: 231-232.

Hoffmann, E., 2005. Fisk, fiskeri og epifauna - Limfjorden 1984-2004. Report 147-05, Danish Institute for Fisheries Research, Charlottenlund: 19 pp (in Danish).

Holland, B. S., M. N. Dawson, G. L. Crow \& D. K. Hofmann, 2004. Global phylogeography of Cassiopea: molecular evidence for cryptic species and multiple invasions of the Hawaiian Islands. Marine Biology 145: 1119-1128.

Hosia, A., 2007. Gelatinous zooplankton in western Norwegian fjords: ecology, systematics and comparisons with adjacent waters. PhD Thesis, University of Bergen, Bergen.

Hsieh, Y. H. P., F. M. Leong \& J. Rudloe, 2001. Jellyfish as food. Hydrobiologia 451: 11-17.

Ishii, H., T. Ohba \& T. Kobayasi, 2008. Effects of low dissolved oxygen on planula settlement, polyp growth and asexual reproduction of Aurelia aurita. Plankton \& Benthos Research 3: 107-113.

Jørgensen, S. E., 2008. Overview of the model types available for development of ecological models. Ecological Modelling 215: 3-9.

Kendall, D., 1990. Shrimp retention characteristics of the Morrison soft TED - a selective webbing exclusion panel inserted in a shrimp trawl net. Fisheries Research 9: 13-21.

Lee, C. C., 1990. Fuzzy logic in control systems: fuzzy logic controller - Part I. IEEE Transactions on Systems, Man, and Cybernetics 20: 404-418. 
Lee, C. I., E. Pakhomov, A. Atkinson \& V. Siegel, 2010. Longterm relationships between the marine environment, krill and salps in the Southern Ocean. Journal of Marine Biology 2010, Article ID 410129: 18 pp.

Licandro, P., D. V. P. Conway, M. N. D. Yahia, M. L. F. de Puelles, S. Gasparini, J. H. Hecq, P. Tranter \& R. R. Kirby, 2010. A blooming jellyfish in the northeast Atlantic and Mediterranean. Biology Letters 6: 688-691.

Lo, W. T., J. E. Purcell, J. J. Hung, H. M. Su \& P. K. Hsu, 2008. Enhancement of jellyfish (Aurelia aurita) populations by extensive aquaculture rafts in a coastal lagoon in Taiwan. ICES Journal of Marine Science 65: 453-461.

Loeb, V., V. Siegel, O. Holm-Hansen, R. Hewitt, W. Fraser, W. Trivelpiece \& S. Trivelpiece, 1997. Effects of sea-ice extent and krill or salp dominance on the Antarctic food web. Nature 387: 897-900.

Lynam, C. P., S. J. Hay \& A. S. Brierley, 2004. Interannual variability in abundance of North Sea jellyfish and links to the North Atlantic Oscillation. Limnology and Oceanography 49: 637-643.

Lynam, C. P., S. J. Hay \& A. S. Brierley, 2005. Jellyfish abundance and climatic variation: contrasting responses in oceanographically distinct regions of the North Sea, and possible implications for fisheries. Journal of the Marine Biological Association of the United Kingdom 85: 435-450.

Mackie, G. O., 1974. Locomotion, floatation, and dispersal. In Muscatine, L. \& H. M. Lenhoff (eds), Coelenterate Biology: Reviews and New Perspectives. Academic Press, New York: 313-357.

Macrokanis, C. J., N. L. Hall \& J. K. Mein, 2004. Irukandji syndrome in northern Western Australia: an emerging health problem. Medical Journal of Australia 181: 699-702.

Maranger, R., N. Caraco, J. Duhamel \& M. Amyot, 2008. Nitrogen transfer from sea to land via commercial fisheries. Nature Geoscience 1: 111-113.

Matsushita, Y. \& N. Honda, 2006. Method of designing and manufacturing JET (Jellyfish Excluder for Towed fishing gear) for various towed fishing gears. Bulletin of Fisheries Research Agency 16: 19-27 (in Japanese with English abstract).

Mianzan, H. W. \& R. A. Guerrero, 2000. Environmental patterns and biomass distribution of gelatinous macrozooplankton. Three study cases in the South-western Atlantic Ocean. Scientia Marina 64: 215-224.

Mills, C. E., 1995. Medusae, siphonophores, and ctenophores as planktivorous predators in changing global ecosystems. ICES Journal of Marine Science 52: 575-581.

Mills, C. E., 2001. Jellyfish blooms: are populations increasing globally in response to changing ocean conditions? Hydrobiologia 451: 55-68.

Møller, L. F. \& H. U. Riisgård, 2007a. Impact of jellyfish and mussels on algal blooms caused by seasonal oxygen depletion and nutrient release from the sediment in a Danish fjord. Journal of Experimental Marine Biology and Ecology 351: 92-105.

Møller, L. F. \& H. U. Riisgård, 2007b. Population dynamics, growth and predation impact of the common jellyfish Aurelia aurita and two hydromedusae, Sarsia tubulosa, and Aequorea vitrina in Limfjorden (Denmark). Marine Ecology Progress Series 346: 153-165.

Nagata, R. M., M. A. Haddad \& M. Nogueira, 2009. The nuisance of medusae to shrimp trawls in central part of southern Brazilian Bight, from the perspective of artisanal fishermen. Pan-American Journal of Aquatic Sciences 4: 312-325.

Nomura, H. \& T. Ishimaru, 1998. Monitoring the occurrence of medusae and ctenophores in Tokyo Bay, central Japan, in recent 15 years. Oceanography in Japan 7: 99-104 (in Japanese with English abstract).

Ohta, N., M. Sato, K. Ushida, M. Kokubo, T. Baba, K. Taniguchi, M. Urai, K. Kihira \& J. Mochida, 2009. Jellyfish mucin may have potential disease-modifying effects on osteoarthritis. BMC Biotechnology 9: 98.

Oliveira, O. M. P., 2007. The presence of the ctenophore Mnemiopsis leidyi in the Oslofjorden and considerations on the initial invasion pathways to the North and Baltic Seas. Aquatic Invasions 2: 185-189.

Omori, M. \& W. M. Hamner, 1982. Patchy distribution of zooplankton: behavior, population assessment and sampling problems. Marine Biology 72: 193-200.

Palomares, M. L. D. \& D. Pauly, 2009. The growth of jellyfishes. Hydrobiologia 616: 11-21.

Pauly, D., 1995. Anecdotes and the shifting base-line syndrome of fisheries. Trends in Ecology \& Evolution 10: 430.

Pauly, D., W. M. Graham, S. Libralato, L. Morissette \& M. L. D. Palomares, 2009a. Jellyfish in ecosystems, online databases, and ecosystem models. Hydrobiologia 616: 67-85.

Pauly, D., J. Alder, S. Booth, W. W. L. Cheung, V. Christensen, C. Close, U. R. Sumaila, W. Swartz, A. Tavakolie, R. Watson, L. Wood \& D. Zeller, 2009b. Fisheries in Large Marine Ecosystems: descriptions and diagnoses. In Sherman, K. \& G. Hempel (eds), The UNEP Large Marine Ecosystem Report: A Perspective on Changing Conditions in LMEs of the World's Regional Seas. United Nations Environment Programme Regional Seas Report and Studies No. 182, Nairobi: 23-40.

Pierce, J., 2009. Prediction, location, collection and transport of jellyfish (Cnidaria) and their polyps. Zoo Biology 28: 163-176.

Pramod, G., 2010. Illegal, unreported and unregulated marine fish catches in the Indian Exclusive Economic Zone. Field Report, Policy and Ecosystem Restoration in Fisheries, Fisheries Centre, University of British Columbia, Vancouver: $30 \mathrm{pp}$.

Pugh, P. R., 1989. Gelatinous zooplankton - the forgotten fauna. Progress in Underwater Science 14: 67-78.

Purcell, J. E., 2005. Climate effects on formation of jellyfish and ctenophore blooms: a review. Journal of the Marine Biological Association of the United Kingdom 85: 461-476.

Purcell, J. E., 2009. Extension of methods for jellyfish and ctenophore trophic ecology to large-scale research. Hydrobiologia 616: 23-50.

Purcell, J. E., 2012. Jellyfish and ctenophore blooms coincide with human proliferations and environmental perturbations. Annual Review of Marine Science 4: 209-235.

Purcell, J. E. \& M. N. Arai, 2001. Interactions of pelagic cnidarians and ctenophores with fish: a review. Hydrobiologia 451: $27-44$. 
Purcell, J. E., S. Uye \& W. T. Lo, 2007. Anthropogenic causes of jellyfish blooms and their direct consequences for humans: a review. Marine Ecology Progress Series 350: 153-174.

Quiñones, J., H. Mianzan, M. Acha, S. Purca \& W. M. Graham, 2010. El Viejo, El Niño and jellyfishes: dramatic environmental-driven changes in jellyfish abundances off Peru. Presentation, Third International Jellyfish Blooms Symposium, Mar del Plata, July 15, 2010.

Richardson, A. J., A. Bakun, G. C. Hays \& M. J. Gibbons, 2009. The jellyfish joyride: causes, consequences and management responses to a more gelatinous future. Trends in Ecology \& Evolution 24: 312-322.

Riisgård, H. U., L. Bøttiger, C. V. Madsen \& J. Purcell, 2007. Invasive ctenophore Mnemiopsis leidyi in Limfjorden (Denmark) in late summer 2007 - assessment of abundance and predation effects. Aquatic Invasions 2: 395-401.

Riisgård, H. U., P. Andersen \& E. Hoffmann, 2012. From fish to jellyfish in the eutrophicated Limfjorden (Denmark). Estuaries and Coasts. doi:10.1007/s12237-012-9480-4.

Schlüter, M. H., A. Merico, M. Reginatto, M. Boersma, K. H. Wiltshire \& W. Greve, 2010. Phenological shifts of three interacting zooplankton groups in relation to climate change. Global Change Biology 16: 3144-3153.

Sherman, K. \& G. Hempel (eds), 2009. The UNEP Large Marine Ecosystem Report: A Perspective on Changing Conditions in LMEs of the World's Regional Seas. United Nations Environment Programme Regional Seas Report and Studies No. 182, Nairobi: 872 pp.

Sherman, K. \& Q. Tang (eds), 1999. Large Marine Ecosystems of the Pacific Rim: Assessment, Sustainability, and Management. Blackwell Science, Cambridge: 465 pp.

Sørnes, T. A., D. L. Aksnes, U. Båmstedt \& M. J. Youngbluth, 2007. Causes for mass occurrences of the jellyfish $P e$ riphylla periphylla: a hypothesis that involves optically conditioned retention. Journal of Plankton Research 29: 157-167.

Spinner, K., 2010. Currents steering sea nettles our way. The Herald Tribune, Sarasota County, October 20, 2010.

Sugahara, T., M. Ueno, Y. Goto, R. Shiraishi, M. Doi, K. Akiyama \& S. Yamauchi, 2006. Immunostimulation effect of jellyfish collagen. Bioscience, Biotechnology, and Biochemistry 70: 2131-2137.

Tendal, O. S., K. R. Jensen \& H. U. Riisgård, 2007. Invasive ctenophore Mnemiopsis leidyi widely distributed in Danish waters. Aquatic Invasions 2: 455-460.
UNESCO, 1968. Zooplankton sampling. United Nations Educational, Scientific and Cultural Organization, Paris: 174 pp.

Uye, S. \& U. Ueta, 2004. Recent increase of jellyfish populations and their nuisance to fisheries in the Inland Sea of Japan. Bulletin of the Japanese Society of Fisheries Oceanography 68: 9-19. (in Japanese with English abstract).

Uye, S., M. Shimizu \& T. Watanabe, 2010. Tackling the giant jellyfish (Nemopilema nomurai) plague: cause, forecast and countermeasure. Plenary presentation, Third International Jellyfish Blooms Symposium, Mar del Plata, July 14, 2010.

van der Werf, H. M. G. \& C. Zimmer, 1998. An indicator of pesticide environmental impact based on a fuzzy expert system. Chemosphere 36: 2225-2249.

van Walraven, L., V. T. Langenberg \& H. W. van der Veer, 2010. Major changes in occurrence, seasonal patterns and species composition of gelatinous zooplankton in the western Dutch Wadden Sea from 1960 until present. Presentation, Third International Jellyfish Blooms Symposium, Mar del Plata, July 14, 2010.

Ward, J. M., J. E. Kirkley, R. Metzner \& S. Pascoe, 2004. Measuring and assessing capacity in fisheries. 1. Basic concepts and management options. FAO Fisheries Technical Paper No. 433/1. Food and Agriculture Organization, Rome: $40 \mathrm{pp}$.

Watson, R., A. Kitchingman, A. Gelchu \& D. Pauly, 2004. Mapping global fisheries: sharpening our focus. Fish and Fisheries 5: 168-177.

Young, G. A. \& J. W. Hagadorn, 2010. The fossil record of cnidarian medusae. Palaeoworld 19: 212-221.

Youngbluth, M. J. \& U. Båmstedt, 2001. Distribution, abundance, behavior and metabolism of Periphylla periphylla, a mesopelagic coronate medusa in a Norwegian fjord. Hydrobiologia 451: 321-333.

Zadeh, L. A., 1965. Fuzzy sets. Information and Control 8: 338-353.

Zimmer, M., 2005. Glowing Genes: A Revolution in Biotechnology. Prometheus Books, Amherst. 